\title{
TERMOGRAVIMETRIA APLICADA AO BIODIESEL DE GIRASSOL ADITIVADO COM EXTRATOS NATURAIS E ANTIOXIDANTE SINTÉTICO
}

\author{
N. S. SUVEGES ${ }^{1}$ e M. L. C. P. da SILVA ${ }^{1}$ \\ ${ }^{1}$ Universidade de São Paulo, Departamento de Engenharia Química \\ E-mail para contato: nsiktar@yahoo.com.br
}

\begin{abstract}
RESUMO - A demanda por energia sempre foi uma preocupação mundial e as maiores fontes de energia são oriundas de matérias-primas fósseis como o petróleo, o carvão e o gás natural, ou seja, todas obtidas de fontes não renováveis. Por este motivo, os estudos para prolongar a vida útil das fontes renováveis de energia são de grande relevância. Este trabalho tem como objetivo estudar e comparar a estabilidade termo-oxidativa do biodiesel de girassol aditivado com $1.000 \mathrm{mg} / \mathrm{L}$ e $2.000 \mathrm{mg} / \mathrm{L}$ de extratos vegetais da casca de laranja, erva mate, alecrim com o biodiesel aditivado com as mesmas quantidades de butil hidroxi tolueno (BHT), um antioxidante sintético comumente utilizado na indústria. Para realizar o acompanhamento da estabilidade termo-oxidativa do biodiesel, exposto ao aquecimento ao longo dos 60 dias, foi utilizada a termogravimetria. Constatou-se que as melhores adições ocorreram com a concentração de $2.000 \mathrm{mg} / \mathrm{L}$ e dentre os extratos vegetais, a erva mate apresentou o melhor resultado.
\end{abstract}

\section{INTRODUÇÃO}

O biodiesel apresenta vantagens frente ao combustível fóssil, pois se destaca pelo fato de ser produzido a partir de fontes renováveis de energia, de não necessitar de grandes modificações nos motores a diesel existentes e emitir menores quantidades de poluentes a natureza (RAMOS et al.; 2003).

A transesterificação é o processo de obtenção do biodiesel mais utilizada e ela pode ser realizada por catálise heterogênea ou homogênea (podendo ser ácida ou básica), sendo a catálise homogênea a mais empregada industrialmente tanto por razões econômicas quanto pelo menor tempo gasto na reação.

Uma das desvantagens e preocupações na utilização do biodiesel está na maior propensão ao processo de oxidação do que o combustível fóssil, pois a oxidação pode elevar a acidez do material, formar depósitos no sistema de injeção do motor e aumento na viscosidade (resultado da polimerização oxidativa) o que leva a uma menor eficiência do biocombustível no motor.

Os processos de oxidação e polimerização ocorrem principalmente na presença de cadeias de ácidos graxos insaturados que compõe a matéria-prima utilizada na produção do biodiesel, pois 


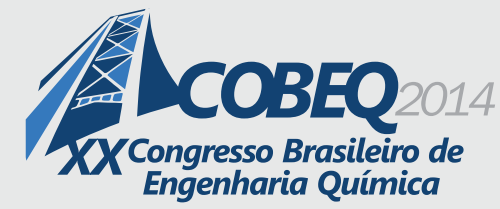

possuem maior propensão de reagir com o oxigênio do ar atmosférico, devido a maior reatividade das duplas ligações.

A degradação oxidativa não ocorre espontaneamente com ácidos graxos saturados, uma vez que a formação de radicais livres é energeticamente desfavorável. Em contrapartida, a presença de duplas ligações na cadeia diminui a energia necessária para a quebra das ligações $\mathrm{C}-\mathrm{H}$ nas posições alílicas e bis-alílicas facilitando sua oxidação (CALIXTO, 2011).

A oxidação das cadeias dos ácidos graxos é um processo complexo composto por uma variedade de mecanismos. Este processo pode ser influenciado por vários fatores, além da composição dos ácidos graxos da matéria-prima utilizada, como a: luz, temperatura, teor de água, peróxidos, condições de armazenamento (área de contato entre o biodiesel e o ar atmosférico) e metais. A adição de antioxidantes ao produto final e a seleção adequada da matéria-prima lipídica, surgem como alternativas para melhorar a estabilidade à oxidação do biodiesel (ATADASHI; AROUA; AZIZ, 2010).

Com o objetivo de se prolongar a estabilidade termo-oxidativa e de se trabalhar com o maior número de produtos renováveis na produção do biodiesel é que surgiu a ideia de trabalhar com os antioxidantes naturais, ou seja, os extratos vegetais que são ricos em compostos fenólicos (principais responsáveis pela ação antioxidante) e comparar com a ação do antioxidante sintético por meio da termogravimetria.

\section{MATERIAIS E MÉTODOS}

\subsection{Produção do biodiesel de girassol obtido por rota metílica}

Em um reator de vidro encamisado com capacidade para $300 \mathrm{~mL}$ e com agitador de pás duplas, adicionou-se $100 \mathrm{~g}$ do óleo vegetal de girassol e em seguida uma solução de metóxido de potássio $($ metanol $+\mathrm{KOH})$ para a reação de transesterificação. A razão molar utilizada de metanol para o óleo vegetal foi de 5:1 e a razão molar de óleo vegetal para o $\mathrm{KOH}$ foi de 1:0,13.

$\mathrm{O}$ reator foi previamente aquecido à $58^{\circ} \mathrm{C}$ contendo o óleo vegetal sob agitação moderada. A reação de transesterificação ocorreu em 45 minutos. Na sequência, transferiu-se a solução do reator para um funil de separação, deixando a solução em repouso e então o glicerol foi separado do biodiesel. A purificação ocorreu em um béquer sob agitação lenta, adicionando água destilada com o auxílio de uma bureta volumétrica. O biodiesel foi novamente transferido para um funil de separação e permanecendo em repouso. A fase aquosa foi separada do biodiesel e este foi encaminhado para uma estufa a $100^{\circ} \mathrm{C}$ durante 1 hora para a retirada do excesso de água e o produto final pode ser visto na Figura 1 (PAIVA, 2010). 


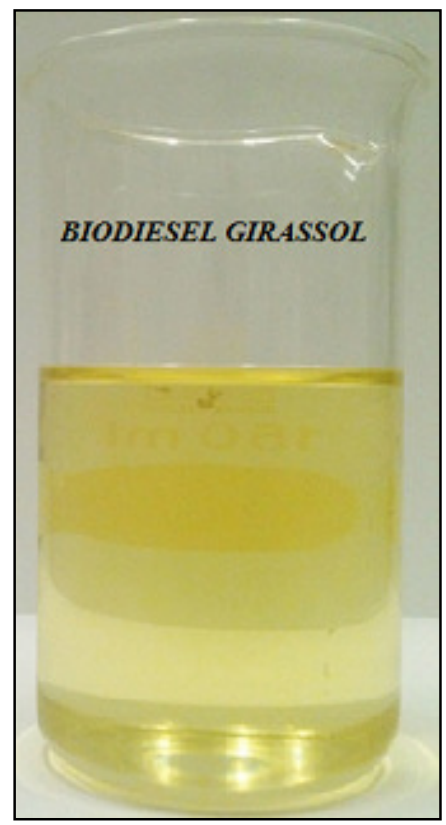

Figura 1 - Biodiesel de girassol produzido no laboratório.

\subsection{Obtenção dos extratos vegetais}

As cascas de laranja e as folhas de alecrim utilizadas neste trabalho foram secas em estufa a 30 ${ }^{\circ} \mathrm{C}$ por uma semana para a retirada do excesso de umidade e a erva mate foi utilizada in natura, ou seja, assim como foram obtidas comercialmente e podem ser visualizadas na Figura 2. As cascas de laranja antes de serem secas foram limpas para a retirada do bagaço residual (parte branca e bagaço) e posteriormente trituradas em um moinho manual.
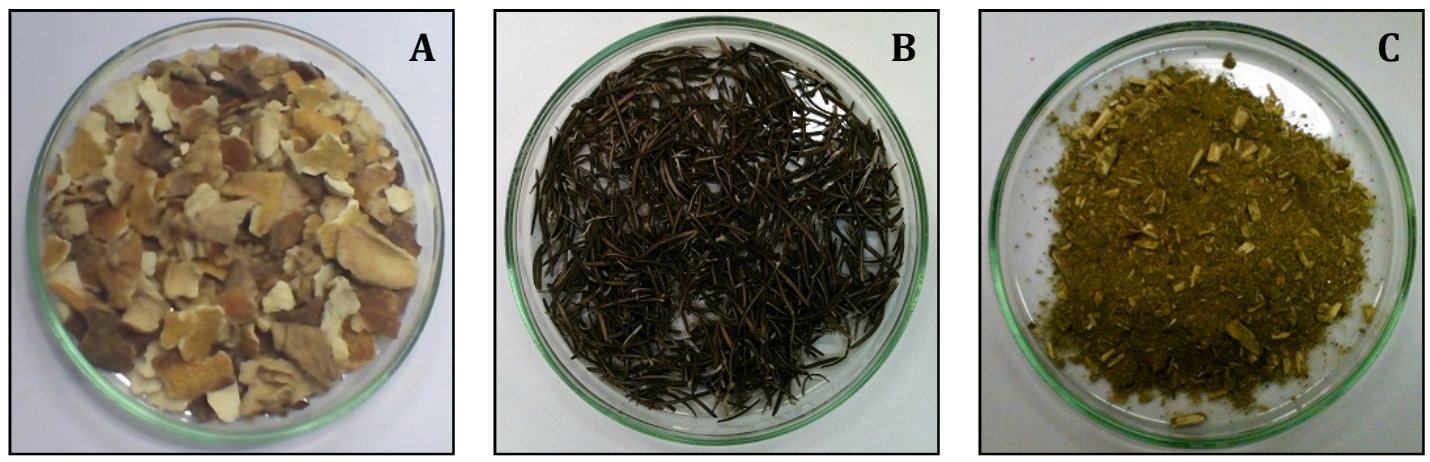

Figura 2 - A) Cascas de laranja, B) Folhas de alecrim e C) Erva mate.

A partir destes produtos vegetais foram obtidos os extratos vegetais pelo método Soxhlet. O método Soxhlet consiste em um tipo de extração sólido-líquido muito utilizado para obtenção de extratos vegetais. Para a obtenção dos extratos primeiramente pesou-se 10,00 g das folhas de alecrim, 


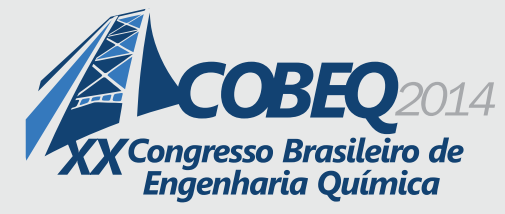

19 a 22 de outubro de 2014

Florianópolis/SC

casca de laranja ou erva mate em um béquer. O material pesado foi colocado em papel de filtro enrolado na forma de cartucho e em seguida colocado no extrator Soxhlet. Antes de acoplar o extrator ao condensador adicionou-se o diclorometano extrator até que o cartucho ficasse totalmente submerso no solvente. Em seguida adicionou-se ao balão o solvente orgânico e conectou-se o extrator Soxhlet. O sistema ficou sob aquecimento $\left(40{ }^{\circ} \mathrm{C}\right)$ por aproximadamente duas horas e meia. Após este período, interrompeu-se a extração exatamente após o esvaziamento da câmara de extração. Retirou-se o cartucho contendo a amostra e reaqueceu-se até que a câmara de extração estivesse quase cheia. Remontou-se o aparelho e repetiu a operação de destilação do solvente até que o balão ficasse quase seco. Desligou-se o aquecimento, aguardou-se o tempo para esfriar o balão e o desconectou para retirada do extrato de interesse (PALLEROS, 1999).

\subsection{Adições dos extratos vegetais e do BHT ao biodiesel}

Os extratos da casca de laranja, folhas de alecrim e erva mate obtidos a partir do método Soxhlet foram adicionados ao biodiesel de girassol nas concentrações de $1.000 \mathrm{mg} / \mathrm{L}$ e $2.000 \mathrm{mg} / \mathrm{L}$ utilizando frascos de Erlemenyer e agitador magnético. Após a dissolução destes extratos no biodiesel, a mistura foi encaminhada para a estufa à temperatura de $60^{\circ} \mathrm{C}$ durante 60 dias.

\subsection{Termogravimetria (TGA)}

A temogravimetria baseia-se no estudo da variação da massa de uma amostra e é o resultado de uma transformação física (sublimação, evaporação, condensação) ou química (degradação, decomposição, oxidação) em função do tempo ou da temperatura (MENDHAM et al., 2000). A termogravimetria do biodiesel foi realizada em uma termobalança modelo TGA-50 marca SHIMADZU, para se determinar a perda de massa dos compostos quando submetidos a uma taxa de aquecimento constante durante um intervalo de temperatura. $O$ perfil da degradação térmica foi investigado no intervalo desde a temperatura ambiente até $600{ }^{\circ} \mathrm{C}$, com taxa de aquecimento 10 ${ }^{\circ} \mathrm{C} / \mathrm{min}$, com um fluxo de ar sintético de $50 \mathrm{~mL} / \mathrm{min}$.

\subsection{Massa específica, viscosidade cinemática e índice de acidez}

Com o objetivo de se verificar a conformidade do biodiesel de girassol com os parâmetros da resolução ANP (Agência Nacional de Petróleo, Gás Natural e Biocombustíveis) n 14 de 11 de maio de 2012 foram analisadas a massa específica, viscosidade cinemática e o índice de acidez do B100 produzido.

\section{RESULTADOS E DISCUSSÕES}

\subsection{Resultados das análises do biodiesel de girassol}

A Tabela 1 apresenta os resultados das análises realizadas com o biodiesel de girassol antes das adições com os extratos vegetais, onde entre parênteses estão indicados os valores de referência segundo normas da ANP, para a qualificação do biodiesel. Todos os resultados obtidos para o B100 
estão em conformidade com a especificação do biodiesel apresentada pela resolução ANP ${ }^{\circ} 14$ de 11 de maio de 2012.

Tabela 1 - Especificação do biodiesel (entre parênteses) e resultados do biodiesel de girassol.

\begin{tabular}{cc}
\hline ESPECIFICAÇÃO BIODIESEL & B100 GIRASSOL \\
\hline Massa específica a $20^{\circ} \mathrm{C}\left(850\right.$ a $\left.900 \mathrm{~kg} / \mathrm{m}^{3}\right)$ & 881 \\
Viscosidade cinemática a $40^{\circ} \mathrm{C}\left(3,0\right.$ a $\left.6,0 \mathrm{~mm}^{2} / \mathrm{s}\right)$ & 5,4 \\
Índice de acidez, máx. 0,50 $\mathrm{mg} \mathrm{KOH} / \mathrm{g}$ & 0,14
\end{tabular}

O perfil da curva TGA e DTG ( $1^{\text {a }}$ derivada da curva TGA) do B100 se apresenta com um único evento térmico conforme pode ser visualizado na Figura 3, onde a Ti encontrada pela curva TGA foi de $206{ }^{\circ} \mathrm{C}$ e a temperatura de maior velocidade de perda de massa, encontrada a partir da curva DTG, foi de $242{ }^{\circ} \mathrm{C}$.

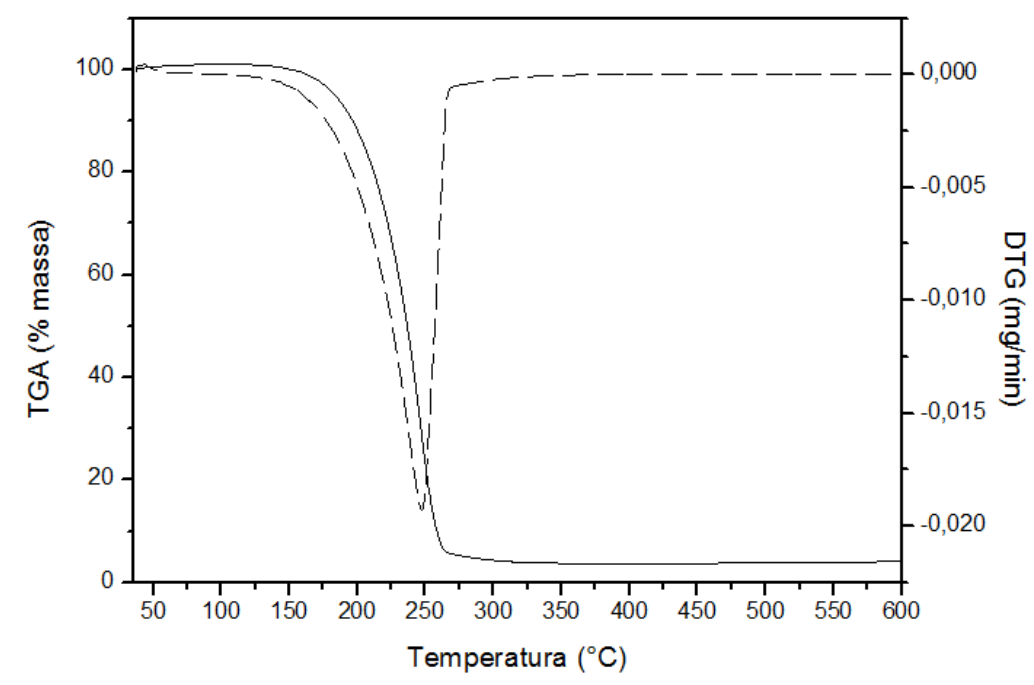

Figura 3 - TGA/DTG do B100 de canola.

\subsection{TGA do B100 de girassol com BHT, extratos da casca de laranja, erva mate e folhas de alecrim expostos à temperatura de $60^{\circ} \mathrm{C}$}

Com a termogravimetria do B100 de girassol exposto à temperatura de $60{ }^{\circ} \mathrm{C}$ fica evidente a eficiência dos antioxidantes em inibir o processo de oxidação, pois o B100 puro já no $7^{\circ}$ dia apresenta o menor valor de Ti, tal fato comprova maior taxa de velocidade de degradação do B100 puro, apresentando valor de Ti igual a $193{ }^{\circ} \mathrm{C}$ e também os menores valores de Ti no decorrer do $30^{\circ}$ e $60^{\circ}$ 
dia de exposição, conforme pode ser visualizado na Tabela 2. Com base nos resultados obtidos, pode se dizer que o produto aditivado, seja com BHT ou com extrato vegetal, apresentou maior estabilidade que o B100 puro.

Com a utilização de antioxidantes fica evidente que o BHT supera a ação contra a oxidação melhor que os extratos vegetais, pois pelos valores de Ti, a amostra com BHT é a que apresenta no $60^{\circ}$ dia e na concentração de $2.000 \mathrm{mg} / \mathrm{L}$ o valor mais próximo $\left(\mathrm{Ti}=199^{\circ} \mathrm{C}\right)$ ao da $\mathrm{Ti}$ do $\mathrm{B} 100$ antes da aditivação $\left(\mathrm{Ti}=206^{\circ} \mathrm{C}\right)$.

Assim como ocorreu para o BHT, as concentrações de $2.000 \mathrm{mg} / \mathrm{L}$ de extratos vegetais foram as que tiveram melhor efetividade na proteção do biodiesel, com exceção das amostras contendo extrato de folhas de alecrim. Comparando os valores obtidos pelo produto com extratos vegetais, o produto contendo o extrato de erva mate foi o que apresentou menor queda da Ti quando comparado com o valor da Ti do B100 antes da aditivação $\left(\mathrm{Ti}=206^{\circ} \mathrm{C}\right)$. A amostra que apresentou maior queda de Ti no decorrer dos 60 dias de exposição e contendo extrato vegetal foi a amostra do B100 de girassol contendo $2.000 \mathrm{mg} / \mathrm{L}$ do extrato de alecrim resultado da Ti foi de $206{ }^{\circ} \mathrm{C}$ para $181{ }^{\circ} \mathrm{C}$, ou seja, queda de $25^{\circ} \mathrm{C}$.

Tabela 2 - Valores de Ti do B100 de girassol puro e com aditivos.

\begin{tabular}{|c|ccc}
\hline \multicolumn{4}{c}{$\mathrm{Ti}\left({ }^{\circ} \mathrm{C}\right)$} \\
\hline $\begin{array}{c}\text { Período } \\
\text { B100 GIRASSOL }\end{array}$ & 7 dias & 30 dias & 60 dias \\
\hline & 193 & 182 & 176 \\
\hline $\begin{array}{c}\text { GIRASSOL + BHT (1000) } \\
\text { GIRASSOL + BHT (2000) }\end{array}$ & 203 & 201 & 192 \\
\hline & 204 & 205 & 199 \\
\hline GIRASSOL + ALECRIM (1000) & 202 & 191 & 183 \\
GIRASSOL + ALECRIM (2000) & 203 & 192 & 181 \\
\hline $\begin{array}{l}\text { GIRASSOL + CASCA LAR (1000) } \\
\text { GIRASSOL + CASCA LAR (2000) }\end{array}$ & 197 & 186 & 185 \\
\hline & 203 & 189 & 187 \\
\hline $\begin{array}{l}\text { GIRASSOL + ERVA MATE (1000) } \\
\text { GIRASSOL + ERVA MATE (2000) }\end{array}$ & 201 & 187 & 183 \\
\hline
\end{tabular}

Os perfis da curva termogravimétrica de todas as amostras se apresentaram com um evento térmico até o $7^{\circ}$ dia. No $30^{\circ}$ dia as únicas amostras que apresentavam um evento térmico foram as que continham BHT como antioxidante o que é comprovado pelos melhores valores de Ti ao longo dos 60 dias. As outras amostras com aditivo já apresentavam a formação do $2^{\circ}$ evento térmico (sendo em média o $1^{\circ}$ entre a temperatura ambiente e $270{ }^{\circ} \mathrm{C}$, o $2^{\circ}$ entre $270{ }^{\circ} \mathrm{C}$ e $600{ }^{\circ} \mathrm{C}$ ) e a amostra de controle já apresentava 3 eventos térmicos (sendo o $1^{\circ}$ entre a temperatura ambiente e $270{ }^{\circ} \mathrm{C}$, o $2^{\circ}$ entre $270^{\circ} \mathrm{C}$ e $420^{\circ} \mathrm{C}$ e o $3^{\circ}$ entre $420^{\circ} \mathrm{C}$ e $600^{\circ} \mathrm{C}$ ) e no $60^{\circ}$ dia a amostra do $\mathrm{B} 100$ puro permaneceu 
com 3 eventos térmicos, porém com queda de Ti na ordem de $30^{\circ} \mathrm{C}$ as amostras com extrato de erva permaneceram com 2 eventos térmicos e as amostras com extrato de folhas de alecrim e de casca de laranja apresentaram a formação do $3^{\circ}$ evento térmico (sendo em média o $1^{\circ}$ entre a temperatura ambiente e $270{ }^{\circ} \mathrm{C}$, o $2^{\circ}$ entre $270{ }^{\circ} \mathrm{C}$ e $420{ }^{\circ} \mathrm{C}$ e o $3^{\circ}$ entre $420{ }^{\circ} \mathrm{C}$ e $600{ }^{\circ} \mathrm{C}$ ) conforme pode ser melhor visualizado na Figura 4. As amostras que apresentaram pela curva TGA, formação de mais um evento térmico, também apresentaram quedas significativas nos valores de Ti
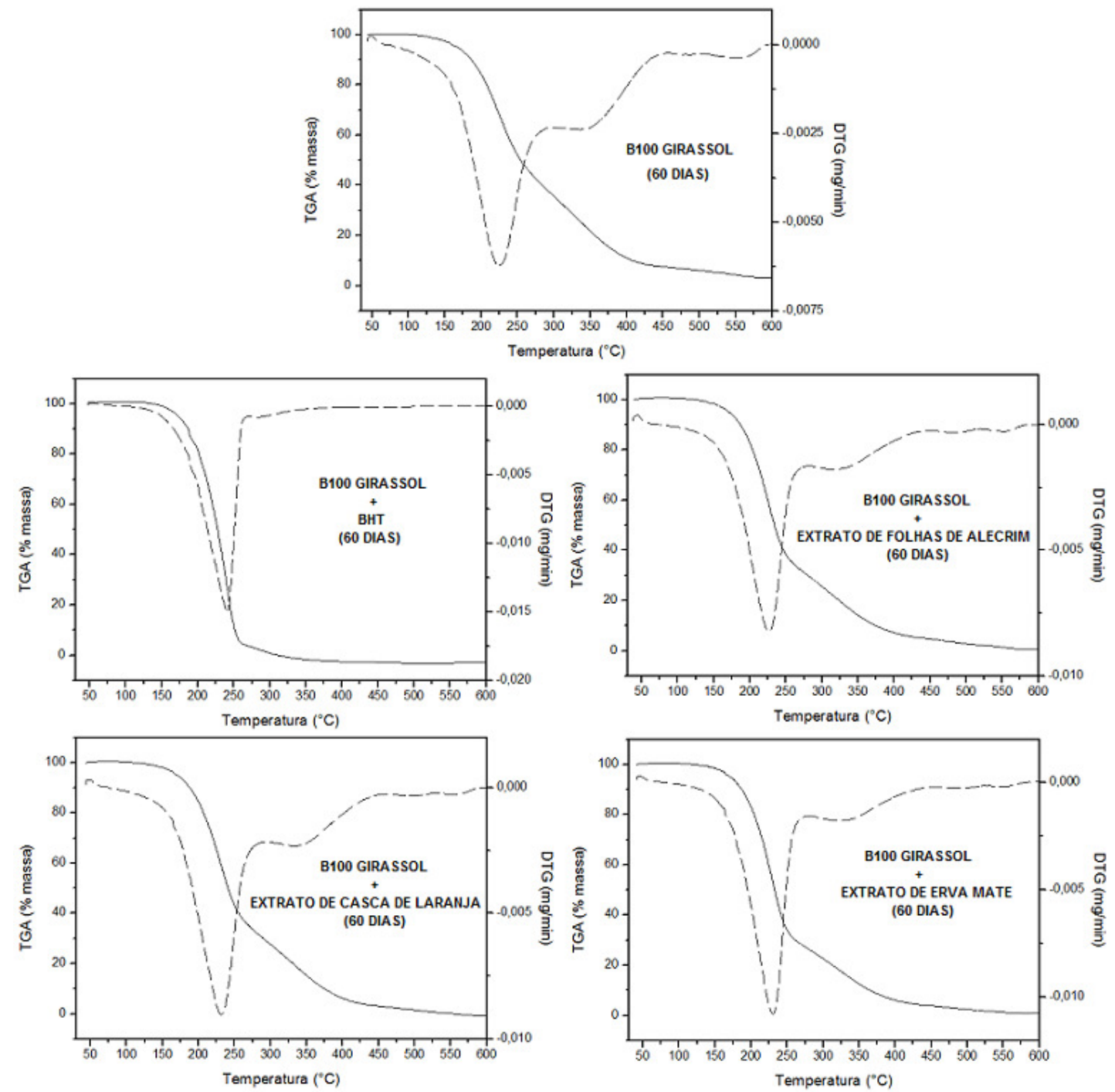

Figura 4 - Perfil das curvas termogravimétricas do B100 de girassol no $60^{\circ}$ dia.

\section{CONCLUSÃO}

Pela curva TGA/DTG observa-se que o biodiesel de girassol quando exposto a temperatura de 60 
${ }^{\circ} \mathrm{C}$ sofreu oxidação;

As amostra do B100 de girassol indicam que dentre os extratos vegetais, o extrato de erva mate na concentração de $2.000 \mathrm{mg} / \mathrm{L}$ apresentou a melhor ação antioxidante;

Todos os extratos vegetais estudados apresentaram ação antioxidante, porém nenhum superou a ação antioxidante do BHT.

\section{REFERÊNCIAS}

ATADASHI, I. M.; AROUA, M. K.; AZIZ, A. A. High quality biodiesel and its diesel engine application: A review. Renewable and Sustainable Energy Reviews, v. 14, p. 1999-2008, 2010.

CALIXTO, C. D. Óleo de quiabo como fonte alternativa para produção de biodiesel e avaliação de antioxidantes naturais em biodiesel etílico de soja. 121 f. Dissertação (Mestrado em Química) Centro de Ciências Exatas e da Natureza - Universidade Federal da Paraíba. João Pessoa - PB, 2011.

MENDHAM, J.; DENNEY, R. C.; BARNES, J. D.; THOMAS, M. J. K. VOGEL. Análise química quantitativa. 6. ed. Rio de Janeiro: LTC, 2012. 488p.

PAIVA, E. J. M. Estudo da produção de biodiesel a partir de óleo de babaçu e etanol utilizando a transesterificação alcalina tradicional com agitação mecânica e assistida por ultrassons. $173 \mathrm{f}$. Dissertação (Mestrado em Ciências do Programa de Pós-Graduação em Engenharia Química) Escola de Engenharia de Lorena - Universidade de São Paulo. Lorena - SP, 2010.

PALLEROS, D. R. Experimental Organic Chemistry. Santa Cruz: John Wiley, 1999. 836 p.

RAMOS, L. P.; KUCEK, K.T.; DOMINGOS, A. K.; WILHELM, H. M. Biodiesel: Um Projeto de Sustentabilidade Econômica e Sócio, Ambiental para o Brasil. Biotecnologia, Ciência e Desenvolvimento. Revista Biotecnologia Ciência \& Desenvolvimento, v.31, p.28-37, 2003. 